\title{
Substrate effects in the photoenhanced ozonation of pyrene
}

\author{
S. A. Styler ${ }^{1}$, M.-E. Loiseaux ${ }^{1}$, and D. J. Donaldson ${ }^{1,2}$ \\ ${ }^{1}$ Department of Chemistry, University of Toronto, Toronto, Ontario, Canada \\ ${ }^{2}$ Department of Physical and Environmental Sciences, University of Toronto Scarborough, Toronto, Ontario, Canada
}

Received: 29 October 2010 - Published in Atmos. Chem. Phys. Discuss.: 15 November 2010

Revised: 30 January 2011 - Accepted: 31 January 2011 - Published: 14 February 2011

\begin{abstract}
We report the effects of actinic illumination on the heterogeneous ozonation kinetics of solid pyrene films and pyrene adsorbed at air-octanol and air-aqueous interfaces. Upon illumination, the ozonation of solid pyrene films and pyrene at the air-aqueous interface proceeds more quickly than in darkness; no such enhancement is observed for pyrene at the air-octanol interface. Under dark conditions, the reaction of pyrene at all three interfaces proceeds via a Langmuir-Hinshelwood-type surface mechanism. In the presence of light, Langmuir-Hinshelwood kinetics are observed for solid pyrene films but a linear dependence upon gas-phase ozone concentration is observed at the air-aqueous interface. We interpret these results as evidence of the importance of charge-transfer pathways for the ozonation of excited-state pyrene. The dramatically different behaviour of pyrene at the surface of these three simple reaction environments highlights the difficulties inherent in representing complex reactive surfaces in the laboratory, and suggests caution in extrapolating laboratory results to environmental surfaces.
\end{abstract}

\section{Introduction}

In high-density urban environments, the percentage of land area covered by impervious surfaces - roads, rooftops, sidewalks, windows, and other surfaces that hinder the infiltration of water into soil (Arnold and Gibbons, 1996) - can reach 98\% (Boyd et al., 1993). In 1998, Law and Diamond postulated that an organic film develops on these surfaces via the direct condensation of semi-volatile chemicals and/or via the deposition of secondary organic aerosols, which are in turn formed by the nucleation or condensation onto particles

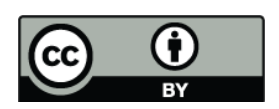

Correspondence to: D. J. Donaldson (jdonalds@chem.utoronto.ca) of the lower-vapour-pressure products of gas-phase reactions (Law and Diamond, 1998). This organic coating, commonly referred to as "urban film", has been shown to enhance both the particle capture efficiency of the surface and the sorption of gas-phase chemicals to the surface, and thereby serve as a reservoir for hydrophobic organic compounds (Butt et al., 2004; Liu et al., 2003b).

Chemical characterization of the organic fraction of urban film has revealed the presence of a variety of alkanes; a number of polar functional groups, including alcohols, esters, carboxylic acids, and carbohydrates; a large fraction of polymeric material; and a wide variety of compounds of toxicological significance (Diamond et al., 2000; Liu et al., 2003a; Lam et al., 2005; Simpson et al., 2006; Unger and Gustafsson, 2008; Gingrich and Diamond, 2001). Of particular interest to this study is the polycyclic aromatic hydrocarbon (PAH) profile observed in urban films: total PAH concentration has been shown to rise along a rural-urban gradient (Gingrich and Diamond, 2001) and can reach values as high as $62000 \mathrm{ng} \mathrm{m}^{-2}$ in highly polluted urban environments (Diamond et al., 2000).

Generally, urban film contains an "aged" PAH profile as compared to that present in "fresh" vehicle exhaust: less reactive PAHs such as pyrene, phenanthrene, and fluoranthene dominate in the film while more reactive PAHs such as anthracene and benzo[ $a]$ pyrene are depleted (Liu et al., 2003b; Diamond et al., 2000; Gingrich and Diamond, 2001). This abundance pattern has been attributed to the rapid photooxidation of reactive PAH species, both in the gas phase and in the film itself (Diamond et al., 2000). Indeed, the results of one modelling study suggest that the large surfacearea-to-volume ratio of urban film $\left(\sim 1.4 \times 10^{7}\right)$ serves to promote chemical loss by re-volatilization, wash-off, and photoinduced reactions (Diamond et al., 2001).

Motivated by these observations, our group has explored the role that organic films play in heterogeneous atmospheric reactive processes (Donaldson et al., 2005; Kahan et al.,

Published by Copernicus Publications on behalf of the European Geosciences Union. 
2006; Kwamena et al., 2007a; Styler et al., 2009). The heterogeneous ozonation of PAHs in solid films (Styler et al., 2009) and incorporated into artificial "window grime" (Kahan et al., 2006) has been shown to proceed considerably faster than in the gas phase; in fact, the results of a modelling study suggest that ozonation on surface films is a major loss process for lower-volatility PAH species (Kwamena et al., 2007a). Given that the products of PAH ozonation are themselves photoactive (Mmereki et al., 2004), these results imply that oxidative processes occurring within urban films may not only significantly influence the lifetime and relative abundance of PAH species but also promote other heterogeneous photoprocesses.

The products of PAH ozonation, which typically display enhanced toxicity (Luster-Teasley et al., 2005; LusterTeasley et al., 2002), would not be expected to partition into the gas phase. Rather, their residence time in the film would be expected to be limited by rain-induced washoff, which has been shown to transfer the vast majority of PAH species to urban surface waters regardless of polarity (Labencki et al., unpublished manuscript). This phenomenon has the potential to act as a pathway for contamination of urban soils and vegetation.

In recent years, a wide variety of studies have investigated heterogeneous photochemical processes occurring on solid organic surfaces (Nieto-Gligorovski et al., 2008; Brigante et al., 2008; Stemmler et al., 2006; Jammoul et al., 2008; George et al., 2005; D'Anna et al., 2009) and organic compounds sorbed to silica particles (Net et al., 2009; Net et al., 2010; Nieto-Gligorovski et al., 2010), where these surfaces have been envisaged as laboratory proxies for organic aerosol and urban film surfaces. These studies have shown that the heterogeneous reactive uptake of $\mathrm{O}_{3}$ and $\mathrm{NO}_{2}$ by a variety of photoactive organics is enhanced in the presence of light (Nieto-Gligorovski et al., 2008; Brigante et al., 2008; Stemmler et al., 2006; Jammoul et al., 2008; George et al., 2005; D'Anna et al., 2009; Net et al., 2009; Net et al., 2010; Nieto-Gligorovski et al., 2010), and have provided indications that such light-enhanced processes may alter aerosol wettability (Nieto-Gligorovski et al., 2008) and optical properties (Nieto-Gligorovski et al., 2010). To date, however, the basic assumption underlying laboratory work in this area that the reaction environment provided by simple proxy systems is sufficiently representative of that provided by real environmental surfaces - has yet to be comprehensively examined.

Guided by early experiments by Diamond et al. (Diamond et al., 2000), which showed that the urban film-air and octanol-air partition coefficients were comparable for a variety of PAH species, our group has previously used octanol as a proxy for the organic component of urban surface films (Kahan et al., 2006; Handley et al., 2007). This, with the recent discovery that PAHs associate strongly with black carbon aerosol particles in the organic component of urban films (Unger and Gustafsson, 2008), leads one to expect that both solid PAH films and PAH-containing octanol films may be appropriate laboratory proxies for urban film surfaces. In this study, we test the assumption that photoenhanced processes are similar in these substrates by examining the influence of light upon the ozonation kinetics of pyrene, a representative PAH, at air-octanol, air-solid film, and air-aqueous interfaces.

\section{Experimental}

\subsection{Apparatus}

The glancing-angle laser-induced fluorescence technique used in this study has been previously used by our group to investigate a range of heterogeneous oxidative processes (Kahan et al., 2006; Styler et al., 2009; Mmereki and Donaldson, 2003). All experiments described herein were conducted in the $\sim 500 \mathrm{~mL}$ Teflon reaction chamber recently employed by Styler et al. (Styler et al., 2009) to study the ozonation kinetics of solid pyrene films. A quartz window present on the top of the reaction chamber allows for the illumination of samples. The chamber is also equipped with inlet and outlet ports for the introduction and venting of gaseous reagents. Gas-phase ozone was generated by passing a flow of highpurity oxygen ( $1 \mathrm{~L} \mathrm{~min}^{-1}$, as measured by a mass flow meter) through a variable ozone generator. Prior to its introduction to the sample chamber, the ozone flow was directed through a 10-cm quartz-windowed absorption cell, where its concentration was determined by measuring the attenuation of the output of a 254-nm Hg pen-ray lamp passed through the cell.

Sample excitation was accomplished using either a pulsed nitrogen laser $(337 \mathrm{~nm})$ or a Nd:YAG-pumped tunable optical parametric oscillator (operated at $266 \mathrm{~nm}$ ), which were aligned such that the incoming beam passed through a quartz window, impinged on the sample surface at a glancing angle, and exited the chamber through a second quartz window opposite the first. The lasers were operated at a repetition rate of $\sim 10 \mathrm{~Hz}$ and had pulse energies of $\sim 260 \mu \mathrm{J}$ pulse $^{-1}$ and $\sim 3 \mathrm{~mJ}_{\text {pulse }}{ }^{-1}$, respectively.

Pyrene fluorescence was collected perpendicular to the sample by a $7-\mathrm{mm}$ diameter liquid light guide positioned $\sim 1$ $\mathrm{cm}$ above it. The fluorescence was imaged into a monochromator and the wavelength-resolved intensity was then detected by a photomultiplier tube, the output of which was sent to a digital oscilloscope. The resulting fluorescence decay curves were averaged over 16 laser shots; a $25-70 \mathrm{~ns}$ segment of each such averaged curve was sampled by a LabVIEW data-acquisition program and stored for later analysis.

\subsection{Sample preparation}

Octanol-based films (Kahan et al., 2006; Handley et al., 2007) were prepared by dispensing $20 \mu \mathrm{L}$ of a $10^{-5} \mathrm{M}$ or $10^{-2} \mathrm{M}$ solution of pyrene in 1-octanol onto a microscope slide that had been previously greased with $\sim 1 \mathrm{mg}$ silicone 
stopcock grease (Dow Corning). A spatula was then used to smear the pyrene solution across the surface of the slide such that it became well mixed with the stopcock grease. Solid pyrene films were prepared by dispensing $20 \mu \mathrm{L}$ of a $2.5 \mathrm{mM}$ solution of pyrene in methanol onto a clean microscope slide and allowing the methanol to evaporate. The surface coverage of films prepared using this technique $\left(\sim 2.5 \mu \mathrm{g} \mathrm{cm}^{-2}\right)$ is of the same order of magnitude as the surface coverage used for our previous investigation of the ozonation of solid pyrene films (Styler et al., 2009). In order to study the ozonation kinetics of pyrene at the air-aqueous interface, $2.4 \mathrm{~mL}$ of a $2.6 \times 10^{-7} \mathrm{M}$ solution of pyrene in $18 \mathrm{M} \Omega$ deionized water was used to fill a shallow Petri dish positioned below the liquid light guide. One set of experiments was also conducted with a five times more dilute pyrene solution.

\subsection{Fluorescence spectra and ozonation kinetics studies}

Wavelength-resolved fluorescence spectra of pyrene at the surface of the three substrates investigated in this study were obtained under an oxygen atmosphere. For each sample, the monochromator was manually scanned to monitor fluorescence intensity at $1-\mathrm{nm}$ intervals over the wavelength range of interest.

Since pyrene fluorescence is efficiently quenched by oxygen (Kahan et al., 2006), all kinetics experiments began by allowing pure oxygen to flow through the reaction chamber. Once the pyrene fluorescence intensity reached a constant value, the ozone generator was turned on. The heterogeneous ozonation of pyrene at the surface of dilute octanol films and at the air-aqueous interface was followed by monitoring the time-dependent decay of fluorescence from monomeric pyrene (vide infra) upon exposure to gas-phase ozone. Experiments at the air-aqueous interface were performed at ozone concentrations ranging from $1.8 \times 10^{15} \mathrm{molec} \mathrm{cm}^{-3}$ to $5.8 \times 10^{15} \mathrm{molec} \mathrm{cm}^{-3}$; fluorescence was measured at either $392 \mathrm{~nm}$ or $372 \mathrm{~nm}$. Experiments at the air-octanol interface were performed using $\sim 8 \times 10^{15} \mathrm{molec} \mathrm{cm}^{-3}$ ozone and monitored at $384 \mathrm{~nm}$. The heterogeneous ozonation of solid pyrene films and pyrene at the surface of concentrated octanol films was followed by monitoring the time-dependent decrease in excimer fluorescence at $466 \mathrm{~nm}$ (vide infra) upon exposure to $\sim 6 \times 10^{15}$ and $\sim 8 \times 10^{15} \mathrm{molec} \mathrm{cm}^{-3}$ ozone, respectively. All reactions were performed at room temperature and atmospheric pressure.

Samples were illuminated using the optically filtered $(\lambda>295 \mathrm{~nm})$ output of a $150 \mathrm{~W}$ xenon arc lamp (Oriel Corporation). The output of the light source was blocked for $\sim 5 \mathrm{~s}$ prior to the acquisition of fluorescence intensity data in order to ensure that pyrene fluorescence excited by the laser was the only signal collected by the liquid light guide. (a)
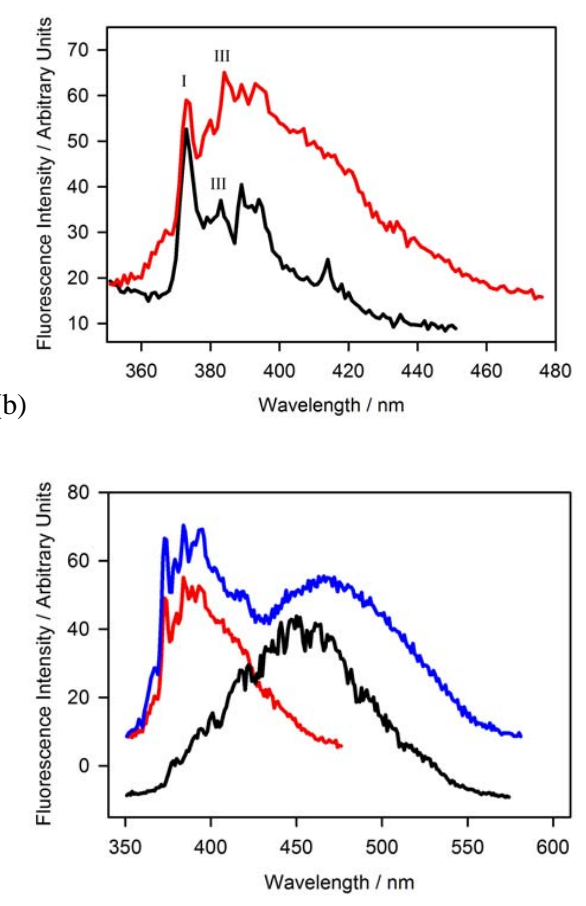

Fig. 1. Fluorescence emission spectra of pyrene measured at the surface of (a) $2.6 \times 10^{-7} \mathrm{M}$ solution of pyrene in deionized water (black) excited at $337 \mathrm{~nm}$ and $10^{-5} \mathrm{M}$ pyrene in octanol (red) spread on silicone grease and excited at $337 \mathrm{~nm}$; (b) $10^{-5} \mathrm{M}$ (red) and $10^{-2} \mathrm{M}$ (blue) pyrene in octanol spread on silicone grease and excited at $337 \mathrm{~nm}$, and $2.5 \mu \mathrm{g} \mathrm{cm} \mathrm{cm}^{-2}$ surface coverage solid pyrene film (black) prepared via evaporation from methanol solution and excited at $266 \mathrm{~nm}$.

\subsection{Chemicals}

1-octanol (99\%, Aldrich), pyrene (98\%, Aldrich), and methanol (ACS grade, Aldrich) were used without purification. Oxygen gas (99.995\%, BOC Gases) was used as delivered.

\section{Results}

\subsection{Fluorescence spectra}

The vibronic fine structure of pyrene monomer fluorescence shows a strong dependence upon the local solvent environment: in particular, the ratio of intensities of the third (III) to the first (I) peaks in the fluorescence emission spectrum is lower in more polar environments than in less polar ones (Mmereki and Donaldson, 2002). Figure 1a compares the fluorescence emission spectrum observed for pyrene at the surface of dilute octanol solution with that observed for pyrene at the air-aqueous interface (Kahan et al., 2006). The III/I ratio observed for pyrene at the air-aqueous interface 


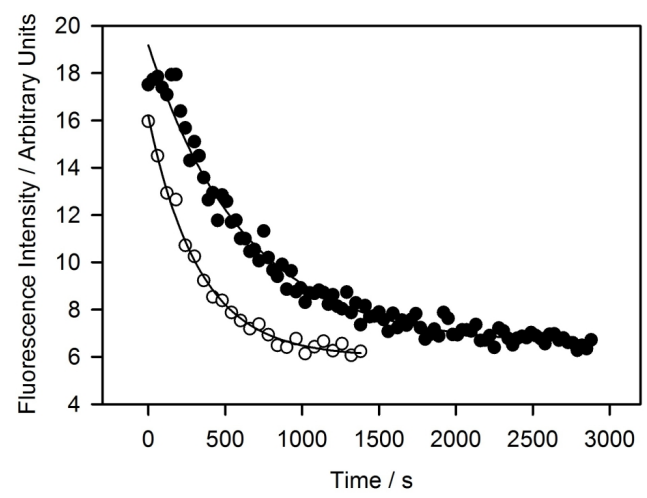

Fig. 2. Decay in fluorescence emission intensity at the surface of $2.6 \times 10^{-7} \mathrm{M}$ pyrene in deionized water $(337 \mathrm{~nm}$ excitation; $392 \mathrm{~nm}$ emission) upon exposure to $\sim 6 \times 10^{15}$ molecules $\mathrm{cm}^{-3}$ ozone. The solid circles show the dark reaction while the hollow circles show the light reaction. All experiments were performed at room temperature and atmospheric pressure.

$(\sim 0.6)$ is considerably lower than that observed at the surface of dilute octanol films $(\sim 1.2)$. This observation suggests that pyrene experiences a more polar environment at the airaqueous interface than at the air-octanol interface.

Figure $1 \mathrm{~b}$ displays the fluorescence emission spectra of pyrene measured at the surface of dilute and concentrated solutions of pyrene in octanol and of pyrene at the surface of solid film samples. At high bulk solution concentrations, the fluorescence spectrum of pyrene at the surface of octanol films contains a broad, red-shifted, featureless band characteristic of emission from excimeric pyrene (Forster and Kasper, 1955). Solid pyrene films, by contrast, exhibit unstructured, excimer-type fluorescence exclusively (Takahashi et al., 1980).

\subsection{Dark ozonation kinetics}

The heterogeneous ozonation kinetics of pyrene were determined by fitting the time-dependent loss in fluorescence intensity upon exposure to ozone to the exponential function:

$I=I_{0} e^{-k_{\mathrm{obs}} t}+c$

Here, $I_{0}$ is the initial fluorescence intensity, $I$ is the fluorescence intensity after time $t, k_{\mathrm{obs}}$ is the observed fluorescence decay rate due to reaction, and $c$ is a constant that accounts for variations in background signal intensities. The values of $k_{\text {obs }}$ obtained in this manner are displayed in Table 1.

Because ozone concentrations remained constant during each experiment, $k_{\mathrm{obs}}$ is a pseudo-first-order rate coefficient. As exemplified in Fig. 2 by the quality of the fits for the heterogeneous ozonation of pyrene at the air-aqueous interface, the reaction is first-order with respect to pyrene in all of the environments under study $\left(R^{2}>0.85\right.$ for solid films and $>0.98$ at the air-aqueous and air-octanol interfaces). The value of $k_{\mathrm{obs}}$ at the air-octanol interface compares well with (a)
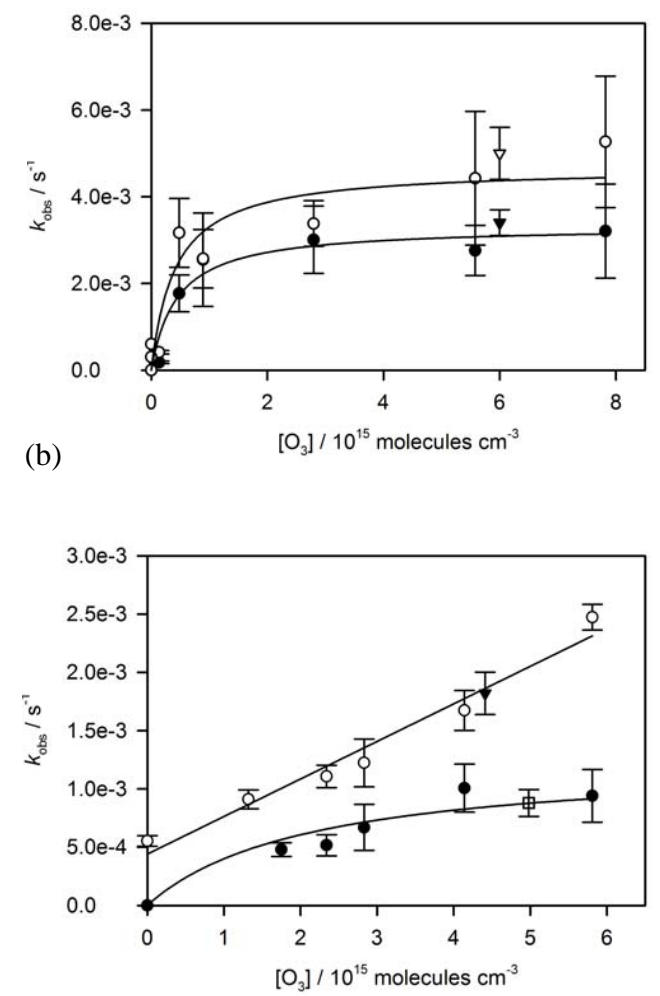

Fig. 3. Heterogeneous loss rate of pyrene at the (a) air-solid film and (b) air-aqueous interface as a function of gas-phase ozone concentration. The solid circles represent the dark reaction while the hollow circles represent the light reaction. In (a), the inverted triangles represent the current experiments; all other data is adapted from Styler et al. (2009). The inverted solid triangle in (b) represents experiments performed using a $320 \mathrm{~nm}$ long-pass optical filter; all other experiments were performed using a $295 \mathrm{~nm}$ filter. The hollow square in (b) represents experiments performed at the surface of five times more dilute aqueous pyrene solutions under dark conditions. All experiments were performed at room temperature and atmospheric pressure.

that previously observed by Kahan et al. (Kahan et al., 2006) for pyrene at the surface of decanol-based urban film proxies. The $k_{\text {obs }}$ obtained for solid pyrene films is similar to that obtained by our group under comparable experimental conditions (Styler et al., 2009).

The solid symbols in Fig. 3a and b show the dependence of $k_{\text {obs }}$ on gas-phase ozone concentration for solid pyrene films (Styler et al., 2009) and pyrene at the air-aqueous interface, respectively, under dark conditions. As shown by the hollow square in Fig. 3b, a comparable $k_{\mathrm{obs}}$ is observed at the surface of a five times more dilute pyrene solution. This result implies that the kinetics observed at the air-aqueous interface are not influenced by pyrene-pyrene interactions. The solid lines in Fig. $3 \mathrm{a}$ and $\mathrm{b}$ illustrate fits to the data assuming $\mathrm{a}$ 
Table 1. Kinetic parameters for pyrene loss as a function of proxy identity.

\begin{tabular}{|c|c|c|c|c|c|}
\hline & $\begin{array}{l}k_{\mathrm{obs}}\left(\mathrm{O}_{3}\right) \\
/ 10^{-3} \mathrm{~s}^{-1}\end{array}$ & $\begin{array}{l}k_{\mathrm{obs}}\left(h v+\mathrm{O}_{3}\right) \\
/ 10^{-3} \mathrm{~s}^{-1}\end{array}$ & $\begin{array}{l}k_{\text {obs }}(h \nu) \\
/ 10^{-3} \mathrm{~s}^{-1}\end{array}$ & $\begin{array}{l}A \\
/ 10^{-3} \mathrm{~s}^{-1}\end{array}$ & $\begin{array}{l}B \\
/ 10^{15} \text { molec cm }^{-3}\end{array}$ \\
\hline solid film & $\begin{array}{l}2.44 \pm 0.92^{\mathrm{a}} \\
3.2 \pm 1.1^{\mathrm{b}, \mathrm{c}}\end{array}$ & $\begin{array}{l}4.71 \pm 0.81^{\mathrm{a}} \\
5.3 \pm 1.5^{\mathrm{b}, \mathrm{c}}\end{array}$ & small evaporative loss & $\begin{array}{l}3.4 \pm 0.3(\text { dark })^{\mathrm{b}, \mathrm{c}} \\
5.0 \pm 0.6(h v)^{\mathrm{b}, \mathrm{c}}\end{array}$ & $\begin{array}{l}0.5 \pm 0.2(\text { dark })^{\mathrm{b}, \mathrm{c}} \\
0.6 \pm 0.3(h v)^{\mathrm{b}, \mathrm{c}}\end{array}$ \\
\hline $\begin{array}{l}\text { air-octanol } \\
\text { interface } \\
\left(10^{-5} \mathrm{M}\right)\end{array}$ & $\begin{array}{l}0.65 \pm 0.18^{b} \\
0.7 \pm 0.1^{d}\end{array}$ & $0.67^{\mathrm{b}}$ & - & - & - \\
\hline $\begin{array}{l}\text { air-octanol } \\
\text { interface }{ }^{b} \\
\left(10^{-2} \mathrm{M}\right)\end{array}$ & 0.63 & 0.55 & - & - & - \\
\hline $\begin{array}{l}\text { air-aqueous } \\
\text { interface }\end{array}$ & $1.7 \pm 0.7^{\mathrm{a}}$ & $2.8 \pm 0.7^{\mathrm{a}}$ & $0.55 \pm 0.04^{\mathrm{a}}$ & $\begin{array}{l}1.5(\text { dark })^{\mathrm{e}} \\
1.3 \pm 0.4(\text { dark })^{\mathrm{a}}\end{array}$ & $\begin{array}{l}2.1(\text { dark })^{\mathrm{e}} \\
2.1 \pm 1.6(\text { dark })^{\mathrm{a}}\end{array}$ \\
\hline
\end{tabular}

${ }^{a}$ At an ozone concentration of $\sim 6 \times 10^{15}$ molecules $\mathrm{cm}^{-3} .^{\mathrm{b}}$ At an ozone concentration of $\sim 8 \times 10^{15}$ molecules $\mathrm{cm}^{-3}$. $^{\mathrm{c}}$ From Styler et al. (2009) ${ }^{\mathrm{d}}$ From Kahan et al. (2006) ${ }^{\mathrm{e}}$ From Donaldson et al. (2005).

Langmuir-Hinshelwood kinetic model, in which ozone adsorbs to the surface prior to reaction and the rate of reaction depends upon the surface concentration of both species (Adamson, 1990). Under these conditions, the dependence of $k_{\text {obs }}$ upon gas-phase ozone concentration can be fit to an equation of the following form:

$k_{\mathrm{obs}}=\frac{A\left[\mathrm{O}_{3}(g)\right]}{B+\left[\mathrm{O}_{3}(g)\right]}$

Here, $A$ is equal to the product of the bimolecular rate constant $k_{I I}$ and the maximum number of surface sites available for ozone adsorption $N_{\text {surf }}$, and $B$ represents a ratio of surface desorption to adsorption from both bulk phases (Mmereki and Donaldson, 2003). As shown in Table 1, the Langmuir-Hinshelwood parameters obtained in the present study for pyrene at the air-aqueous interface agree well with those previously obtained by Donaldson et al. (Donaldson et al., 2005).

\subsection{Ozonation kinetics under illumination}

At the highest ozone concentration employed in these experiments $\left(\sim 8 \times 10^{15}\right.$ molecules $\left.\mathrm{cm}^{-3}\right)$, the average pseudofirst-order rate coefficient for ozonation of pyrene under illumination at the surface of both dilute and concentrated octanol films is the same as that observed in the dark. At an ozone concentration of $\sim 6 \times 10^{15}$ molecules $\mathrm{cm}^{-3}$, the ozone-driven loss of pyrene at the air-aqueous interface and at the surface of solid pyrene films displays a modest enhancement in the presence of light. These results are summarized in Table 1.

The average $k_{\mathrm{obs}}$ for the heterogeneous ozonation of solidfilm pyrene increases from $(2.44 \pm 0.92) \times 10^{-3} \mathrm{~s}^{-1}$ in the dark to $(4.71 \pm 0.81) \times 10^{-3} \mathrm{~s}^{-1}$ upon illumination at an ozone concentration of $\sim 6 \times 10^{15}$ molec $\mathrm{cm}^{-3}$. This enhancement, illustrated by the triangle symbols in Fig. 3a, is comparable to that previously observed by our group for solid-film pyrene under similar conditions: at an ozone concentration of $\sim 8 \times 10^{15}$ molec $\mathrm{cm}^{-3}$, the average $k_{\text {obs }}$ increased from $(3.2 \pm 1.1) \times 10^{-3} \mathrm{~s}^{-1}$ in darkness to $(5.3 \pm 1.5) \times 10^{-3} \mathrm{~s}^{-1}$ in the presence of light (Styler et al., 2009). The photolysis of solid-sorbed pyrene is known to be slow (Reyes et al., 2000; Behymer and Hites, 1988). With no ozone present, we observe only a slow evaporative loss of pyrene upon illumination.

The hollow symbols in Fig. $3 \mathrm{a}$ and $\mathrm{b}$ show the dependence of $k_{\text {obs }}$ on gas-phase ozone concentration for solid pyrene films (Styler et al., 2009) and pyrene at the air-aqueous interface, respectively, under illuminated conditions. As shown by the intercept in Fig. 3b, photochemical loss of pyrene at the water surface in the absence of ozone cannot fully account for the enhancement observed at the air-aqueous interface. Unlike the pseudo-first-order ozonation rate of illuminated pyrene solid films, which displays a LangmuirHinshelwood-type dependence on gas-phase ozone concentration (Styler et al., 2009), the pseudo-first-order ozonation rate of pyrene at the air-aqueous interface varies linearly with gas-phase ozone concentration. At the surface of a substantially more dilute pyrene solution, we again observed a linear dependence of pyrene loss rate on ozone concentration (not shown in Fig. 3).

In order to verify that the enhanced pyrene loss observed under illumination does not arise from reaction of pyrene with $\mathrm{OH}$ produced by the photolysis of ozone and subsequent reaction of $\mathrm{O}\left({ }^{1} \mathrm{D}\right)$ with water vapour, some experiments were performed using a $320 \mathrm{~nm}$ long-pass optical filter. $\mathrm{O}\left({ }^{1} \mathrm{D}\right)$ production under these conditions - estimated using measured filter transmission spectra and literature values for ozone absorption cross section and $\mathrm{O}\left({ }^{1} \mathrm{D}\right)$ quantum yield (Finlayson-Pitts and Pitts, 2000) - is expected to be two 
orders of magnitude lower than $\mathrm{O}\left({ }^{1} \mathrm{D}\right)$ production using the $295 \mathrm{~nm}$ long-pass filter. However, as illustrated by the solid inverted triangle in Fig. 3b, we observed a near-identical $k_{\text {obs }}$ in these experiments, which implies that $\mathrm{OH}$ production does not contribute to the observed kinetics.

\section{Discussion}

\subsection{Heterogeneous ozonation of pyrene under dark conditions}

Previous mechanistic studies of the reaction of gas-phase ozone with solid films of pyrene (Styler et al., 2009), pyrene at the surface of dilute decanol-based urban film proxies (Kahan et al., 2006), and pyrene at the air-aqueous interface (Donaldson et al., 2005) have shown that all three reactions proceed via a Langmuir-Hinshelwood mechanism, in which ozone adsorbs to the surface prior to reaction and the rate of reaction depends upon the surface concentration of both species (Adamson, 1990).

The Langmuir-Hinshelwood $A$ parameter contains the two-dimensional rate coefficient for reaction: as shown in Table 1, its value for solid-film pyrene is approximately three times larger than for pyrene at the air-aqueous interface and approximately five times larger than for pyrene at the surface of octanol films. This result echoes previous observations of enhanced PAH reactivity in the solid state: the $A$ parameters for the heterogeneous ozonation of both benzo $[a]$ pyrene and anthracene are larger when they are sorbed to solid surfaces (Poschl et al., 2001; Kwamena et al., 2006) than when they are incorporated into octanol- or decanol-based films (Kahan et al., 2006).

It is tempting to propose that the heterogeneous ozonation kinetics of PAHs dissolved in organic films might be limited by the diffusion of PAHs from bulk solution to the air-film boundary. After a thorough examination of this issue, however, Kwamena et al. (Kwamena et al., 2007b) concluded that such liquid-phase diffusion constraints are likely not important. This suggests that the mechanism by which the reaction environment influences the heterogeneous reaction of PAHs with adsorbed ozone is chemical in nature.

In organic solvents, the rate-determining step for PAH ozonation is believed to be the formation of a charged $\pi$ or $\sigma$-complex with ozone via electrophilic attack (Pryor et al., 1983). This implies that both the polarity of the reaction environment and the electrophilicity of ozone within the reaction environment may influence the rate of PAH ozonation. If such effects were important at interfaces, one would expect the heterogeneous ozonation rate of PAHs to vary as a function of surface polarity. Our work provides some support for this hypothesis: the pseudo-first-order rate coefficient for ozonation of pyrene at the air-aqueous interface is somewhat larger than that observed for pyrene at the airoctanol interface. However, this observation is far from uni- versal: the Langmuir-Hinshelwood $A$ parameter for the reaction of ozone with anthracene has been observed to be virtually identical $\left(\sim 2.5 \times 10^{-3} \mathrm{~s}^{-1}\right)$ when anthracene is present at the surface of "pure" water, water coated with a monolayer of 1-octanol, or decanol-based urban film proxies (Mmereki and Donaldson, 2003; Kahan et al., 2006). Taken together, these results suggest that the role that the chemical nature of the surface plays in influencing the heterogeneous reaction of PAHs with adsorbed ozone under dark conditions is at best uncertain.

As illustrated in Fig. 1b, we observe broad, featureless, excimer-type fluorescence at the surface of both solid pyrene films and concentrated octanol films. On solid surfaces, excimeric emission by pyrene has been largely attributed to absorption and subsequent emission by weakly bound groundstate associated pairs (Barbas et al., 1994; Reyes et al., 2000). Evidence for the existence of higher aggregates in the solid state is provided by the absorption spectrum of thin pyrene films, which exhibits a long-wavelength tail (Nautiyal and Bisht, 2010). The enhanced ozonation loss rate observed for PAHs in the solid-film environment as compared to the organic-film environment has been previously postulated to arise from an enhanced reactivity of such self-associated PAHs with ozone (Kahan et al., 2006). Indeed, it seems plausible that the extended electronic structure of the solid film and the resultant resonance stabilization of charged reaction intermediates might confer enhanced heterogeneous reactivity toward ozone.

Until recently, ground-state PAH aggregation was not believed to occur in solution: the broad, structureless emission observed for solution-phase pyrene and other PAHs at high concentrations had been attributed exclusively to "dynamic" excimers - transient dimers existing only in the excited state and formed by the interaction of an excited molecule with one in the ground state (Winnik, 1993). A number of recent studies, however, have suggested that ground-state associated pairs and/or aggregates, whose formation has been shown to be promoted by hydrophobic, $\pi$-stacking interactions (Jones and Vullev, 2001), may also contribute to the emission profile of concentrated pyrene solutions (Khakhel', 2001; Boateng, 2007; Andriessen et al., 1992; Krykunova and Khakhel', 1998). The role that these species play in the reactivity of pyrene at the air-organic interface is currently unclear, however, and warrants further study.

\subsection{Heterogeneous ozonation of pyrene under illumination}

Some mechanistic insight into our observations can be provided by considering the various photochemical and photophysical deactivation pathways available to the singletstate monomeric and excimeric pyrene species formed upon absorption of light in the presence of ozone and oxygen. These deactivation pathways are displayed schematically in Scheme 1. 


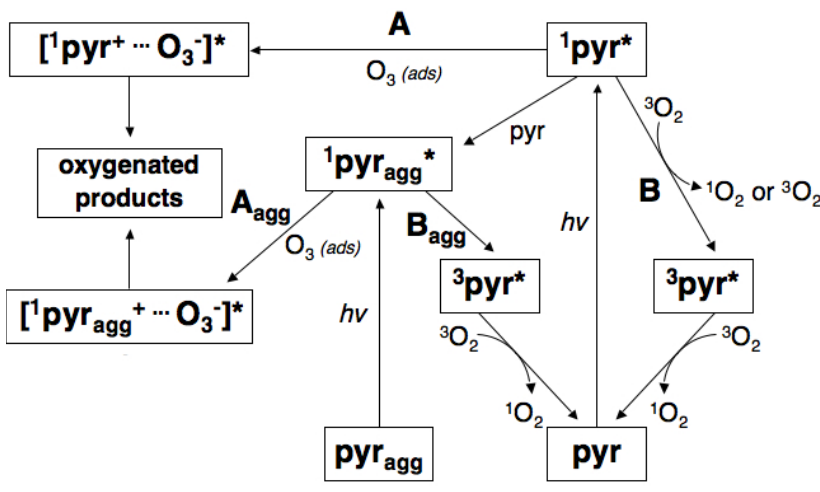

Scheme 1. Photophysical and photochemical deactivation pathways available to excited-state pyrene molecules.

First, singlet-state pyrene may form a charge-transfer complex with adsorbed ozone, which may subsequently undergo reactive decay to yield an oxygenated pyrene radical and molecular oxygen. This pathway, referred to in Scheme 1 and in the following discussion as an A-type pathway, is expected to lead to photoenhanced pyrene loss: indeed, we have previously invoked the existence of a charge-transfer complex between solid pyrene films and adsorbed ozone to explain the observed light-induced enhancement of the heterogeneous reaction rate for these two species (Styler et al., 2009). Of course, singlet-state pyrene may also form a charge-transfer complex with adsorbed oxygen, giving rise to pyrene ions in the absence of ozone. However, in the present experiments, the photochemical loss rate of solid-film pyrene under a pure oxygen atmosphere was insignificant over the time scale of the ozonation reaction.

Singlet-state pyrene may also be deactivated via oxygenassisted intersystem crossing (with or without the production of excited singlet molecular oxygen, $\mathrm{O}_{2}\left({ }^{1} \Delta_{g}\right)$ (Abdel-Shafi et al., 2001; Abdel-Shafi and Wilkinson, 2000)); the resultant lower-energy triplet state may then be quenched by oxygen to yield ground-state pyrene with the concomitant production of $\mathrm{O}_{2}\left({ }^{1} \Delta_{g}\right)$ (Shold, 1978; Abdel-Shafi et al., 2001). Given that pyrene does not react efficiently with $\mathrm{O}_{2}\left({ }^{1} \Delta_{g}\right.$ ) (Reyes et al., 2000; Kubat et al., 2000), this pathway, referred to in Scheme 1 and in the following discussion as a $B$-type pathway, can be viewed purely as a photophysical deactivation process.

The relative importance of $A$-type and $B$-type pathways and thus the propensity of pyrene to undergo photoenhanced ozonation - depends strongly on the nature of the reaction medium. In non-polar solvents such as octanol, $A$-type pathways are insignificant: although there is some evidence for the formation of contact charge-transfer (CCT) complexes between pyrene and dissolved oxygen molecules in cyclohexane solution, the value of the CCT quenching constant is two orders of magnitude smaller than the dynamic, collisionbased quenching constant (Brownrigg and Kenny, 2009).
Our previous observations of order-of-magnitude enhancements in pyrene photolysis rates in bulk aqueous solution over those observed in organic solution (Donaldson et al., 2009) and our present failure to observe a light-induced enhancement in the heterogeneous ozonation of pyrene at the air-octanol interface both provide additional evidence for the solvent dependence of these charge-transfer-type reactions. Persuasive evidence for the predominance of $B$-type pathways in non-polar solvents has been provided by a number of authors: the fraction of excited pyrene singlet states which yields triplet states upon quenching by oxygen, for example, has been shown to be unity in toluene (Potashnik et al., 1971) and cyclohexane (Kikuchi, 1991; Abdel-Shafi et al., 2001).

As shown in Table 1, the heterogeneous ozonation of solid-film pyrene displays a modest enhancement upon illumination. These results are consistent with observations of $A$-type behaviour for solid-sorbed pyrene: pyrene is known to form charge-transfer complexes upon adsorption to reactive sites on silica gel (Ruetten and Thomas, 1998); at higher surface loadings on silica-alumina and $\gamma$-alumina, pyrene radical cations react with parent molecules to form monopositive dimeric radical cations (Mao and Thomas, 1992). Solidphase pyrene is also known to undergo charge-transfer processes with adsorbed gaseous species: the formation of HONO upon reaction of an illuminated pyrene film with $\mathrm{NO}_{2}$, for example, has been attributed to the photoreduction of $\mathrm{NO}_{2}$ by excited-state pyrene (Brigante et al., 2008). Finally, pyrene photooxidation on surfaces is generally believed to proceed via an electron-transfer mechanism (Mao and Thomas, 1995; Reyes et al., 2000; Boscher et al., 2005). On silica gel, the pyrene radical cation has been shown to be an intermediate of the photooxidation process (Mao and Thomas, 1995).

$A$-type pathways are also common in polar solvents: a number of authors (Potashnik et al., 1971; Abdel-Shafi and Wilkinson, 2000; Sato et al., 1995; Shold, 1978) have attributed non-quantitative triplet yields for excitedstate pyrene upon quenching by oxygen in polar solvents to the existence of charge-transfer interactions between pyrene and oxygen that compete with oxygen-enhanced intersystem crossing; in some cases, absorbance attributable to the pyrene cation has been observed (Potashnik et al., 1971). In addition, pyrene photooxidation in aqueous solution is believed to occur via a charge-transfer process (Clark et al., 2007; Sigman et al., 1998). Specifically, it is thought to occur either via the excitation of CCT pairs or via electron transfer to oxygen from the excited singlet state of pyrene; in both cases, the subsequent reaction of the resultant charge-transfer complex between the pyrene cation radical and superoxide yields oxidized products (Sigman et al., 1998).

As shown in Table 1 and illustrated in Fig. 3b, the pseudofirst-order rate coefficient $k_{\text {obs }}$ for the heterogeneous ozonation of pyrene at the air-aqueous interface displays a modest enhancement upon illumination. Interestingly, this enhancement is accompanied by a change in kinetic mechanism: 
as illustrated in Fig. $3 \mathrm{~b}$, while $k_{\text {obs }}$ displays a LangmuirHinshelwood-type dependence upon gas-phase ozone concentration under dark conditions, it increases linearly with gas-phase ozone concentration upon illumination. We attribute this change in mechanism to an increased favourability of $A$-type pathways at the highly polar air-aqueous interface.

The linear dependence of $k_{\text {obs }}$ upon gas-phase ozone concentration observed in the present experiments suggests that the charge-transfer reaction between pyrene and ozone at the air-aqueous interface is sufficiently favourable to occur via a non-adsorptive Eley-Rideal-type mechanism, in which reaction occurs upon the collision of a gas-phase ozone molecule with an adsorbed excited-state pyrene molecule (Adamson, 1990). At the aqueous surface, the ozonide anion thus formed can react to form hydroxyl radical, which can in turn react with adsorbed pyrene. The pyrene radical cation formed as a result of the initial charge-transfer reaction would be expected to react with water to form 1hydroxybenzene and further oxidized products (Sigman et al., 1998). Our proposed mechanism can be summarized as follows:

$\mathrm{Pyr}+h v \rightarrow \mathrm{Pyr}^{*}$

$\mathrm{Pyr}^{*}+\mathrm{O}_{3}$ (ads) $\rightarrow$ oxidized products

$\mathrm{Pyr}^{*}+\mathrm{O}_{3}(g) \rightarrow \mathrm{Pyr}^{+}+\mathrm{O}_{3}^{-}$

$\mathrm{O}_{3}^{-}+\mathrm{H}_{2} \mathrm{O} \rightarrow \mathrm{OH}^{-}+\mathrm{O}_{2}+\mathrm{OH}$

$\mathrm{OH}+\mathrm{Pyr} \rightarrow$ oxidized products

$\mathrm{Pyr}^{+}+\mathrm{H}_{2} \mathrm{O} \rightarrow$ oxidized products

If the electron-transfer/hydrolysis steps (Reactions R3 and R4) are sufficiently fast, the adsorbed concentration of ozone at the illuminated aqueous surface will be small. Under these conditions, loss of pyrene at the interface may be dominated by reaction with hydroxyl radical (Reaction R5) rather than with adsorbed ozone (Reaction R2). In this manner, the Langmuir-Hinshelwood mechanism observed in the dark, which would involve reaction between co-adsorbed pyrene and ozone, would evolve into one in which the ozone dependence reflects the delivery of gas-phase ozone to the surface, where its reduction is very rapid. A similar mechanism has been proposed to explain the photoenhanced reaction of chlorophyll with ozone at the salt water surface, which also shows a linear dependence on gas-phase ozone concentration (Reeser et al., 2009).

In summary, compelling evidence exists for the prevalence of charge-transfer pathways - and thus the possibility for the photoenhanced loss of pyrene via the formation of chargetransfer complexes with adsorbed ozone - for excited-state pyrene at the air-solid film interface. By contrast, the deactivation of excited-state pyrene in non-polar environments is expected to proceed primarily via oxygen-assisted intersystem crossing. Indeed, the results obtained in this study fit well within this conceptual framework: we see a photoinduced enhancement of the heterogeneous ozonation rate of solid-film pyrene but not of pyrene at the non-polar airoctanol film interface. At the highly polar air-aqueous interface, our results suggest that a charge-transfer mechanism between gas-phase ozone and adsorbed pyrene is activated upon illumination. We propose that the photoenhanced loss of pyrene at the air-aqueous interface arises via the reaction of pyrene with photoproduced hydroxyl radical or via the reaction of pyrene cation radical with water.

\section{Conclusions and implications for laboratory studies of heterogeneous environmental photoprocesses}

Under dark conditions, our results suggest that the heterogeneous reactivity of pyrene toward ozone is influenced by a complex set of substrate-substrate and substrate-surface interactions. In the presence of light, the behaviour of pyrene at the surface of the three reaction environments under study differs more dramatically: while the heterogeneous ozonation of solid-film pyrene displays a light enhancement, the ozonation of pyrene at the air-octanol film interface does not; moreover, the ozone-induced loss of pyrene at the illuminated air-aqueous interface not only occurs more quickly than in the dark but also displays a different dependence upon gas-phase ozone concentration.

Our proposed mechanism of photoenhancement, which involves the transfer of charge from pyrene to either gas-phase or adsorbed ozone and which thus would be expected to be more favourable at the air-solid film and air-aqueous interfaces than at the non-polar air-octanol film interface, fits well with these observations. In real environments, however, reactive molecules of interest are not present at bulk concentrations in a single solvent but rather are present as trace solutes in a complex matrix, the other components of which may alter their photophysical and photochemical properties. The work presented here on aqueous surfaces implies that photoenhanced processes may well be important for PAHs dispersed at low concentrations in aqueous environments. However, since real urban films have been shown to contain large quantities of sulfates, nitrates, and metals, which serve to increase the polarity of the medium and thus promote charge-transfer processes, and which may serve as photocatalysts themselves (Lam et al., 2005), our failure to observe light-enhanced ozonation at the air-octanol interface may not be environmentally significant.

In summary, the results obtained in this study suggest that a variety of heterogeneous photoprocesses occurring in urban film proxies may depend strongly upon the type of surface that is used to mimic the urban film environment, and further caution that the use of proxies that only superficially 
resemble urban films may not necessarily give an accurate picture of reactions occurring in the environment.

Acknowledgements. This work was partially funded by NSERC. S.A.S. thanks NSERC for the award of a PGS-D scholarship. We thank J. P. Wong for her preliminary work on PAH solid films.

Edited by: M. Ammann

\section{References}

Abdel-Shafi, A. A. and Wilkinson, F.: Charge transfer effects on the efficiency of singlet oxygen production following oxygen quenching of excited singlet and triplet states of aromatic hydrocarbons in acetonitrile, J. Phys. Chem. A, 104, 5747-5757, 2000.

Abdel-Shafi, A. A., Worrall, D. R., and Wilkinson, F.: Singlet oxygen formation efficiencies following quenching of excited singlet and triplet states of aromatic hydrocarbons by molecular oxygen, J. Photochem. Photobiol. A-Chem., 142, 133-143, 2001.

Adamson, A. W.: Physical Chemistry of Surfaces, 5th ed., John Wiley and Sons, Toronto, Canada, 1990.

Andriessen, R., Ameloot, M., Boens, N., and Deschryver, F. C.: Non-a-priori analysis of fluorescence decay surfaces of excitedstate processes .3. intermolecular excimer formation of pyrene quenched by iodomethane, Journal of Physical Chemistry, 96, 314-326, 1992.

Arnold, C. L. and Gibbons, C. J.: Impervious surface coverage The emergence of a key environmental indicator, J. Am. Plan. Assoc., 62, 243-258, 1996.

Barbas, J. T., Dabestani, R., and Sigman, M. E.: A mechanistic study of photodecomposition of acenaphthylene on a dry silica surface, J. Photochem. Photobiol. A-Chem., 80, 103-111, 1994.

Behymer, T. D. and Hites, R. A.: Photolysis of polycyclic aromatic hydrocarbons adsorbed on fly-ash, Environ. Sci. Technol., 22, 1311-1319, 1988.

Boateng, S.: Photophysical properties of pyrene, 2,7-diazapyrene, and 1,3-bis( $\beta$-naphthyl)propane, MSc thesis, Department of Chemistry, University of North Texas, USA, 2007.

Boscher, A., David, B., and Guittoneau, S.: Photodegradation of pyrene on solid phase, in: Environmental Chemistry, edited by: Lichtfouse, E., Schwarzbauer, J. and Robert, D., Springer Berlin Heidelberg, Germany, 441-448, 2005.

Boyd, M. J., Bufill, M. C., and Knee, R. M.: Pervious and impervious runoff in urban catchments, Hydrol. Sci. J., 38, 463-478, 1993.

Brigante, M., Cazoir, D., D’Anna, B., George, C., and Donaldson, D. J.: Photoenhanced uptake of $\mathrm{NO}_{2}$ by pyrene solid films, J. Phys. Chem. A, 112, 9503-9508, 2008.

Brownrigg, J. T. and Kenny, J. E.: Fluorescence intensities and lifetimes of aromatic hydrocarbons in cyclohexane solution: evidence of contact charge-transfer interactions with oxygen, J. Phys. Chem. A, 113, 1049-1059, 2009.

Butt, C. M., Diamond, M. L., Truong, J., Ikonomou, M. G., Helm, P. A., and Stern, G. A.: Semivolatile organic compounds in window films from lower Manhattan after the September 11th World Trade Center attacks, Environ. Sci. Technol., 38, 3514-3524, 2004.
Clark, C. D., De Bruyn, W. J., Ting, J., and Scholle, W.: Solution medium effects on the photochemical degradation of pyrene in water, J. Photochem. Photobiol. A-Chem., 186, 342-348, 2007.

D’Anna, B., Jammoul, A., George, C., Stemmler, K., Fahrni, S., Ammann, M., and Wisthaler, A.: Light-induced ozone depletion by humic acid films and submicron aerosol particles, J. Geophys. Res.-Atmos., 114(12), D12301, doi:10.1029/2008JD001237, 2009.

Diamond, M. L., Gingrich, S. E., Fertuck, K., McCarry, B. E., Stern, G. A., Billeck, B., Grift, B., Brooker, D., and Yager, T. D.: Evidence for organic film on an impervious urban surface: characterization and potential teratogenic effects, Environ. Sci. Technol., 34, 2900-2908, 2000.

Diamond, M. L., Priemer, D. A., and Law, N. L.: Developing a multimedia model of chemical dynamics in an urban area, Chemosphere, 44, 1655-1667, 2001.

Donaldson, D. J., Mmereki, B. T., Chaudhuri, S. R., Handley, S., and Oh, M.: Uptake and reaction of atmospheric organic vapours on organic films, Faraday Discuss., 130, 227-239, 2005.

Donaldson, D. J., Kahan, T. F., Kwamena, N. O. A., Handley, S. R., and Barbier, C.: Atmospheric chemistry of urban surface films, in: Atmospheric Aerosols, edited by: Valsaraj, K. T., and Kommalapati, R. R., ACS Symposium Series, Washington, DC, USA, 79-89, 2009.

Finlayson-Pitts, B. J., and Pitts, J., and James, N.: Chemistry of the Upper and Lower Atmosphere, Academic Press, San Diego, California, USA, 2000.

Forster, T. and Kasper, K.: Ein Konzentrationsumschlag Der Fluoreszenz Des Pyrens, Zeitschrift Für Elektrochemie, 59, 976-980, 1955.

George, C., Strekowski, R. S., Kleffmann, J., Stemmler, K., and Ammann, M.: Photoenhanced uptake of gaseous NO2 on solidorganic compounds: a photochemical source of HONO?, Faraday Discuss., 130, 195-210, 2005.

Gingrich, S. E. and Diamond, M. L.: Atmospherically derived organic surface films along an urban-rural gradient, Environ. Sci Technol., 35, 4031-4037, 2001.

Handley, S. R., Clifford, D., and Donaldson, D. J.: Photochemical loss of nitric acid on organic films: A possible recycling mechanism for $\mathrm{NO}_{\mathrm{x}}$, Environ. Sci. Technol., 41, 3898-3903, 2007.

Jammoul, A., Gligorovski, S., George, C., and D'Anna, B.: Photosensitized heterogeneous chemistry of ozone on organic films, J. Phys. Chem. A, 112, 1268-1276, 2008.

Jones, G. and Vullev, V. I.: Ground- and excited-state aggregation properties of a pyrene derivative in aqueous media, J. Phys Chem. A, 105, 6402-6406, 2001.

Kahan, T. F., Kwamena, N. O. A., and Donaldson, D. J.: Heterogeneous ozonation kinetics of polycyclic aromatic hydrocarbons on organic films, Atmos. Environ., 40, 3448-3459, 2006.

Khakhel', O. A.: Absorption spectra of pyrene aggregates in saturated solutions, J. Appl. Spectrosc., 68, 280-286, 2001.

Kikuchi, K.: A new method for determining the efficiency of enhanced intersystem crossing in fluorescence quenching by molecular oxygen, Chem. Phys. Lett., 183, 103-106, 1991.

Krykunova, V. and Khakhel', O. A.: Pyrene aggregation in liquid solutions, Functional Materials, 5, 356-358, 1998.

Kubat, P., Civis, S., Muck, A., Barek, J., and Zima, J.: Degradation of pyrene by UV radiation, J. Photochem. Photobiol. A-Chem., $132,33-36,2000$. 
Kwamena, N. O. A., Earp, M. E., Young, C. J., and Abbatt, J. P. D.: Kinetic and product yield study of the heterogeneous gassurface reaction of anthracene and ozone, J. Phys. Chem. A, 110, 3638-3646, 2006.

Kwamena, N. O. A., Clarke, J. P., Kahan, T. F., Diamond, M. L., and Donaldson, D. J.: Assessing the importance of heterogeneous reactions of polycyclic aromatic hydrocarbons in the urban atmosphere using the Multimedia Urban Model, Atmos. Environ., 41, 37-50, 2007a.

Kwamena, N. O. A., Staikova, M. G., Donaldson, D. J., George, I. J., and Abbatt, J. P. D.: Role of the aerosol substrate in the heterogeneous ozonation reactions of surface-bound PAHs, J. Phys. Chem. A, 111, 11050-11058, 2007b.

Labencki, T., Diamond, M. L., Motelay-Massai, A., Truong, J., Branfireun, B., and Dann, T.: Variability in and mechanisms of PAH washoff from urban impervious surfaces, unpublished manuscript.

Lam, B., Diamond, M. L., Simpson, A. J., Makar, P. A., Truong, J., and Hernandez-Martinez, N. A.: Chemical composition of surface films on glass windows and implications for atmospheric chemistry, Atmos. Environ., 39, 6578-6586, 2005.

Law, N. L. and Diamond, M. L.: The role of organic films and the effect on hydrophobic organic compounds in urban areas: an hypothesis, Chemosphere, 36, 2607-2620, 1998.

Liu, Q. T., Chen, R., McCarry, B. E., Diamond, M. L., and Bahavar, B.: Characterization of polar organic compounds in the organic film on indoor and outdoor glass windows, Environ. Sci. Technol., 37, 2340-2349, 2003a.

Liu, Q. T., Diamond, M. L., Gingrich, S. E., Ondov, J. M., Maciejczyk, P., and Stern, G. A.: Accumulation of metals, trace elements and semi-volatile organic compounds on exterior window surfaces in Baltimore, Environ. Poll., 122, 51-61, $2003 \mathrm{~b}$.

Luster-Teasley, S. L., Yao, J. J., Herner, H. H., Trosko, J. E., and Masten, S. J.: Ozonation of chrysene: evaluation of byproduct mixtures and identification of toxic constituent, Environ. Sci. Technol., 36, 869-876, 2002.

Luster-Teasley, S. L., Ganey, P. E., DiOrio, M., Ward, J. S., Maleczka, R. E., Trosko, J. E., and Masten, S. J.: Effect of byproducts from the ozonation of pyrene: biphenyl-2,2',6,6'tetracarbaldehyde and biphenyl-2,2',6,6'-tetracarboxylic acid on gap junction intercellular communication and neutrophil function, Environ. Toxicol. Chem., 24, 733-740, 2005.

Mao, Y. and Thomas, J. K.: Photochemical reactions of pyrene on surfaces of gamma-alumina and silica-alumina, Langmuir, 8, 2501-2508, 1992.

Mao, Y. and Thomas, J. K.: Chemical reactions of molecular oxygen in surface-mediated photolysis of aromatic compounds on silica-based surfaces, J. Phys. Chem., 99, 2048-2056, 1995.

Mmereki, B. T. and Donaldson, D. J.: Laser induced fluorescence of pyrene at an organic coated air-water interface, Phys. Chem. Chem. Phys., 4, 4186-4191, 2002.

Mmereki, B. T. and Donaldson, D. J.: Direct observation of the kinetics of an atmospherically important reaction at the air-aqueous interface, J. Phys. Chem. A, 107, 11038-11042, 2003.

Mmereki, B. T., Donaldson, D. J., Gilman, J. B., Eliason, T. L., and Vaida, V.: Kinetics and products of the reaction of gas-phase ozone with anthracene adsorbed at the air-aqueous interface, Atmos. Environ., 38, 6091-6103, 2004.

Nautiyal, A. and Bisht, P. B.: Steady state and time-resolved stud- ies of pyrene in solution and in single microcrystals, J. Luminescence, 130, 1829-1833, 2010.

Net, S., Nieto-Gligorovski, L., Gligorovski, S., Temime-Rousell, B., Barbati, S., Lazarou, Y. G., and Wortharn, H.: Heterogeneous light-induced ozone processing on the organic coatings in the atmosphere, Atmos. Environ., 43, 1683-1692, 2009.

Net, S., Gligorovski, S., and Wortham, H.: Light-induced heterogeneous ozone processing on organic coated particles: Kinetics and condensed-phase products, Atmos. Environ., 44, 3286-3294, 2010.

Nieto-Gligorovski, L., Net, S., Gligorovski, S., Zetzsch, C., Jammoul, A., D'Anna, B., and George, C.: Interactions of ozone with organic surface films in the presence of simulated sunlight: impact on wettability of aerosols, Phys. Chem. Chem. Phys., 10, 2964-2971, 2008.

Nieto-Gligorovski, L. I., Net, S., Gligorovski, S., Wortham, H., Grothe, H., and Zetzsch, C.: Spectroscopic study of organic coatings on fine particles, exposed to ozone and simulated sunlight, Atmos. Environ., Atmos. Environ., 44, 5451-5459, 2010.

Pöschl, U., Letzel, T., Schauer, C., and Niessner, R.: Interaction of ozone and water vapor with spark discharge soot aerosol particles coated with benzo[a]pyrene: $\mathrm{O}_{3}$ and $\mathrm{H}_{2} \mathrm{O}$ adsorption, benzo[a]pyrene degradation, and atmospheric implications, J Phys. Chem. A, 105, 4029-4041, 2001.

Potashnik, R., Goldschmidt, C. R., and Ottolenghi, M.: Triplet state formation in the quenching of fluorescence by molecular oxygen, Chem. Phys. Lett., 9, 424-425, 1971.

Pryor, W. A., Gleicher, G. J., and Church, D. F.: Reaction of polycyclic aromatic hydrocarbons with ozone - linear free-energy relationships and tests of likely rate-determining steps using simple molecular-orbital correlations, J. Org. Chem., 48, 4198-4202, 1983.

Reeser, D. I., Jammoul, A., Clifford, D., Brigante, M., D’Anna, B., George, C., and Donaldson, D. J.: Photoenhanced reaction of ozone with chlorophyll at the seawater surface, J. Phys. Chem. C, 113, 2071-2077, 2009.

Reyes, C. A., Medina, M., Crespo-Hernandez, C., Cedeno, M. Z., Arce, R., Rosario, O., Steffenson, D. M., Ivanov, I. N., Sigman, M. E., and Dabestani, R.: Photochemistry of pyrene on unactivated and activated silica surfaces, Environ. Sci. Technol., 34, 415-421, 2000.

Ruetten, S. A. and Thomas, J. K.: Fluorescence and triplet quantum yields of arenes on surfaces, J. Phys. Chem. B, 102, 598-606, 1998.

Sato, C., Kikuchi, K., Okamura, K., Takahashi, Y., and Miyashi, T.: New aspects on fluorescence quenching by molecular oxygen .2. Inhibition of long-distance electron-transfer in acetonitrile, J. Phys. Chem., 99, 16925-16931, 1995.

Shold, D. M.: Formation of singlet oxygen from aromatic excimers and monomers, J. Photochem.., 8, 39-48, 1978.

Sigman, M. E., Schuler, P. F., Ghosh, M. M., and Dabestani, R. T.: Mechanism of pyrene photochemical oxidation in aqueous and surfactant solutions, Environ. Sci. Technol., 32, 3980-3985, 1998.

Simpson, A. J., Lam, B., Diamond, M. L., Donaldson, D. J., Lefebvre, B. A., Moser, A. Q., Williams, A. J., Larin, N. I., and Kvasha, M. P.: Assessing the organic composition of urban surface films using nuclear magnetic resonance spectroscopy, Chemosphere, 63, 142-152, 2006. 
Stemmler, K., Ammann, M., Donders, C., Kleffmann, J., and George, C.: Photosensitized reduction of nitrogen dioxide on humic acid as a source of nitrous acid, Nature, 440, 195-198, 2006.

Styler, S. A., Brigante, M., D’ Anna, B., George, C., and Donaldson, D. J.: Photoenhanced ozone loss on solid pyrene films, Phys. Chem. Chem. Phys., 11, 7876-7884, 2009.

Takahashi, Y., Kitamura, T., and Uchida, K.: Excimer emission from evaporated pyrene films, Journal of Luminescence, 21, 425-433, 1980.
Unger, M., and Gustafsson, O.: PAHs in Stockholm window films: Evaluation of the utility of window film content as indicator of PAHs in urban air, Atmos. Environ., 42, 5550-5557, 2008.

Winnik, F. M.: Photophysics of preassociated pyrenes in aqueous polymer solutions and in other organized media, Chem. Rev., 93, 587-614, 1993. 